\title{
Avaliação do Preparo Intestinal para Videocolonoscopia em Crianças
}

\section{Evaluation of Bowel Preparation in Children for Videocolonoscopy}

\author{
JUVENALDAROCHATORRES NETO ${ }^{1}$; ISABEL HORA²; JÚLIOAUGUSTO DO PRADOTORRES ${ }^{3}$; \\ FELIPEAUGUSTODOPRADOTORRES ${ }^{4}$
}

\author{
${ }^{1}$ Professor, doutor e chefe do Serviço de Coloproctologia da UFS ; ${ }^{2}$ Médica da UPEP; ${ }^{3}$ Acadêmico de Medicina da \\ UFS ${ }^{4}$ Acadêmico de Medicina da UFS.
}

\begin{abstract}
TORRES NETO JR; HORA ISABEL; TORRES JAP; TORRES FAP. Avaliação do Preparo Intestinal para Videocolonoscopia em Crianças. Rev bras Coloproct, 2008;28(2): 210-214.

RESUMO: Para a realização adequada da colonoscopia, é necessária uma limpeza colônica satisfatória. Existem vários métodos de preparo intestinal, mas para crianças ainda não existe um ideal. Portanto, buscamos, com este trabalho, um preparo intestinal padrão para esta faixa etária, que proporcione uma limpeza colônica excelente, tenha menos efeitos colaterais, grande aceitabilidade e custo reduzido, garantindo o apoio e a segurança dos familiares sobre o método. Foram avaliadas 46 crianças que se submeteram a videocolonoscopia, no período de 2002 a 2006, no serviço de videocolonoscopia do Hospital Universitário de Sergipe e na UPEP. As crianças foram divididas nos seguintes grupos etários: até um ano (grupo A), crianças de 1 a 5 anos(grupo B) e crianças maiores que 5 anos (grupo C). Nos lactentes e menores que 5 anos, foi usado fosfato de sódio via retal e as crianças maiores que 5 anos receberam solução de manitol via oral. Das 25 crianças que usaram o fosfato de sódio por via retal, o preparo foi excelente em 21 (88\%) pacientes e bom em 1 (4\%) paciente, embora todas as mães tenham relatado uma aplicação difícil. As outras 21 crianças usaram manitol, com resultado excelente em $17(80,9 \%)$ pacientes e bom em um $(4,8 \%)$ paciente; entretanto, todas as crianças apresentaram náuseas e vômitos após sua ingestão, com recusa pelas crianças devido ao grande volume. Alcançou-se o ceco em 41 $(89 \%)$ casos, dos quais, o íleo terminal foi alcançado em 19 (41,3\%) casos. Um preparo intestinal individualizado permitiu alto índice de bom preparo e baixa morbidade.
\end{abstract}

Descritores: colonoscopia, crianças, limpeza intestinal, manitol, fosfato de sódio.

\section{INTRODUÇÃO}

A colonoscopia é um importante procedimento diagnóstico e, em alguns casos, terapêutico ${ }^{2}$, possibilitando o diagnóstico histológico e a remoção endoscópica de pólipos colônicos. ${ }^{1}$ Ela está indicada na pesquisa de lesões mucosas além do alcance do retossigmoidoscópio rígido ou mesmo do flexível, localizadas nas porções proximais dos cólons ou no íleo terminal. ${ }^{3}$

Um cólon limpo é indispensável para a execução de um exame apropriado e seguro. A presença de restos fecais no lúmen cólico dificulta o procedimento, podendo impedir a visibilização de possível lesão, ${ }^{4}$ sendo também necessária para obtenção de tecidos para exame histológico, para remoção de pólipos e de gases voláteis $^{3,4}$

Existem diferentes formas de limpeza colônica: utilizando-se laxantes orais (óleo de castor, senna ou bisacodil) combinados com enemas, purgantes osmóticos (sais de magnésio, manitol), polietilenoglicol (PEG) e solução com fosfato de sódio por via oral. ${ }^{3,4,5}$ Somente os detalhes é que variam em cada serviço, de acordo com o local, o horário e a maneira com que será efetuado. ${ }^{8}$

O preparo ideal para a colonoscopia deve obedecer aos seguintes critérios: dieta laxante de curta

Trabalho realizado no Serviço de videocolonoscopia do Hospital Universitário de Sergipe e na UPEP (Unidade de Proctologia, Endoscopia, Cirurgia e Pediatria). 
duração, drogas laxantes com bom sabor, volume razoável, preparo simples e de poucos efeitos colaterais (anormalidade eletrolítica, náuseas, vômitos, dor abdominal excessiva). ${ }^{5,9}$

Há poucos relatos na literatura sobre preparo colônico para crianças. Ao contrário do paciente adulto, o procedimento é geralmente realizado com anestesia geral ou sedação profunda. Assim, o jejum oral necessário após a ingestão do laxante retarda o início do exame. ${ }^{2}$ Solução contendo polietilenoglicol, habitualmente utilizada em crianças, é administrada com sonda nasogástrica devido à grande quantidade de volume a ser ingerido em curto período de tempo. ${ }^{3,10}$ É, no entanto, método seguro e eficaz. ${ }^{2}$ Preparo com soluções fosfatadas, por via oral, é efetivo em adultos, não sendo recomendada em crianças menores de 2 anos de idade. $^{4}$

Todos os métodos de preparo intestinal disponíveis têm limitações e efeitos colaterais desagradáveis, não havendo um preparo intestinal uniforme para a realização da colonoscopia que seja recomendado para as diversas faixas etárias da criança, do lactente ao adolescente., ${ }^{2,11}$

O objetivo deste trabalho é avaliar a eficácia e a morbidade do preparo intestinal para videocolonoscopia em crianças, escalonado por faixa etária e peculiaridade de aceitação da medicação. Utilizando laxativo à base de sorbitol + laurilsulfato de sódio por via retal em todas as crianças, combinado com o uso de fosfato de sódio retal e/ou manitol oral, visamos estabelecer um preparo padrão mais adequado.

\section{CASUÍSTICA E MÉTODOS}

Neste trabalho, foram avaliadas 46 crianças com idade 2 dias até 12 anos, independentemente do gênero a que foram submetidas ao exame videocolonoscópico, realizado no Serviço de Videocolonoscopia do Hospital Universitário da Universidade Federal Sergipe e na UPEP (Unidade de Pediatria, Endoscopia, Cirurgia e Pediatria), no período de 2002 a 2006.

Utilizamos videocolonoscópio de resolução convencional Olympus ${ }^{\circledR}$, Tóquio, Japão: CF tipo V L/ J, processadora EVIS Exera CV 145, fonte de luz EVIS CLV-160, com lâmpada de xenônio de 300 w; monitor colorido Olympus ${ }^{\circledR}$ OEV 142. A vídeo-impressora de fotografia SONY ${ }^{\circledR}$ UP 51MD foi programada para impressão de foto de tamanho total, com o obje- tivo de melhorar o padrão da fotografia e posterior análise.

O preparo intestinal, em todas as crianças, se iniciou com dieta pastosa sem resíduos e sem leite na véspera do exame, associado ao uso de 01 bisnaga de Minilax ${ }^{\circledR}$, por via retal, $(4,64 \mathrm{~g}$ de sorbitol a $70 \%$ e $0,05 \mathrm{~g}$ de laurilsulfato de sódio por bisnaga). No dia do exame, as crianças ingeriram dieta líquida pela manhã, ingerindo apenas água após o início do preparo e até 2 $\mathrm{h}$ antes do início do exame.

As crianças com idade até 1 ano (grupo A) foram submetidas à lavagem intestinal com $1 / 2$ frasco de solução de fosfato de sódio retal às 7 horas e 1/2 frasco desta solução uma hora antes da realização do exame (às 10 horas).

As crianças com idade entre 1 e 5 anos (grupo B) receberam a lavagem intestinal com 1 frasco de fosfato de sódio retal às $7 \mathrm{~h}$ e 1 frasco uma hora antes do exame (às 10 horas).

Já nas crianças com idade entre cinco e 12 anos (grupo C), o preparo foi iniciado na sua própria residência às 5 horas, com a ingestão de metoclopramida ( $1 \mathrm{~g} / \mathrm{kg}$ de peso), seguida da ingestão de $500 \mathrm{ml}$ de manitol a $10 \%(250 \mathrm{ml}$ de manitol a $20 \%$ diluído em $250 \mathrm{ml}$ de água de côco) por $20 \mathrm{~kg}$ de peso, acrescidos de $20 \mathrm{ml}$ desta solução a cada $\mathrm{kg}$ de peso excedido, numa velocidade de $50 \mathrm{ml}$ de 5 em 5 minutos.

Durante o exame, a condição do preparo intestinal foi avaliada e classificada em: excelente, quando houve apenas um líquido claro, que não atrapalhou a visibilização de toda a mucosa; boa, quando houve líquido com pouco resíduo, mas que se conseguiu aspirar e realizar todo o exame; regular, quando houve fezes líquidas, mas escuras, dificultando a realização do exame; e ruim, quando houve fezes formadas, resíduos sólidos, não se conseguindo completar o exame.

Foi realizada análise descritiva dos resultados.

\section{RESULTADOS}

Neste estudo foram avaliadas 46 crianças que se submeteram a exame colonoscópico no período de 2002 a 2006. A idade variou de 2 dias a 12 anos, com média de 5 anos e 1 mês, sendo $2(4,3 \%)$ crianças com idade até 1 ano (grupo A), $23(50 \%)$ crianças com idade entre 1 e 5 anos (grupo B) e 21(45,7\%) com idade superior a 5 anos (grupo C). Trinta e duas 
(70\%) crianças eram do gênero masculino e 14 (30\%) do gênero feminino. A indicação do exame foi investigação de colite em 28 (60\%) pacientes, diarréia e sangramento retal em 18 (40\%), dor abdominal e perda de peso em 9 (20\%), não sendo relatada a indicação em 4 (10\%) pacientes. Alguns pacientes tinham mais de uma indicação para colonoscopia.

O Minilax ${ }^{\circledR}$ foi de fácil aplicação em 32 (70\%) casos e difícil em 14 (30\%). O início do seu efeito ocorreu em menos de 30 minutos em todas as crianças, e a duração foi de menos de uma hora. Trinta e duas (70\%) crianças só evacuaram uma vez, e 14(30\%) evacuaram três vezes. Houve relato de ardor anal em 14 (30\%) pacientes, dor abdominal em 23 (50\%) e 9 (20\%) não apresentaram nenhum efeito colateral.

O fosfato de sódio retal foi de difícil aplicação em todas as crianças que o usaram (grupos A e B), com início de efeito em menos de 30 minutos e duração variando de $2,5 \mathrm{~h}$ a $3,5 \mathrm{~h}$, com média de $3 \mathrm{~h}$. O número de evacuações variou de 4 a 6 vezes, com média 5 vezes. A última evacuação se apresentou com aspecto de líquido amarelado sem resíduos em 14 (60\%) pacientes e com resíduos fecais em 9 (40\%). Cólica abdominal foi relatada em todos os pacientes.

Nas 21 crianças que utilizaram a solução oral de manitol (grupo C), sua ingestão foi fácil no início, relatando, as mães, que as crianças começaram a recusar pelo grande volume. O início do efeito foi em uma hora e a duração variou de $2,5 \mathrm{~h}$ a $5,5 \mathrm{~h}$, com média de 4 h. O número de evacuações variou de 2 a 10 vezes, com uma média de 6 vezes. $O$ aspecto da última evacuação foi de líquido escuro com resíduos fecais em $8(40 \%)$ pacientes e fezes líquidas amareladas em $13(60 \%)$. Todas as vinte e uma crianças vomitaram após o manitol, sendo que $13(60 \%)$ delas vomitaram apenas uma vez e as outras 8 (40\%) tiveram três episódios de vômito.

Nenhum desses pacientes havia sido submetido a nenhum tipo de preparo intestinal anteriormente.

Das 46 crianças avaliadas, o preparo intestinal com o uso de fosfato de sódio retal (usado nos grupos A e B) foi excelente em 22 (88\%) casos, bom em 1 (4\%) e regular em $2(8 \%)$. A solução de manitol por via oral proporcionou resultado excelente em $17(80,9 \%)$ casos, bom em $1(4,8 \%)$, regular em $2(9,5 \%)$ e péssimo em $1(4,8 \%)$ caso.

O ceco foi alcançado em $41(89 \%)$ exames, tendo em $19(41,3 \%)$ colonoscopias alcançado o íleo terminal. Um $(2,1 \%)$ exame se estendeu apenas ao ângulo esplênico, um $(2,1 \%)$ até o cólon ascendente ,um $(2,1 \%)$ até o cólon descendente e $2(4,3 \%)$ até o retossigmóide.

O exame foi normal em 12 (26\%) crianças. Em outros 12 (26\%) casos, o achado endoscópico foi sugestivo de hiperplasia linfóide de íleo terminal; em 3 (6,5\%), processo inflamatório inespecífico de cólon; e em 13 (28\%) crianças foram encontrados 15 pólipos $\{10(66,7 \%)$ de reto, $5(33,3 \%)$ de cólon $\}$

\section{DISCUSSÃO}

A maioria dos trabalhos encontrados na literatura utiliza na véspera do exame o bisacodil por via oral, como laxativo. Segundo TORRES-NETO et al, 2001, avaliando, em seu trabalho, o início e a duração do efeito do bisacodil em adultos, verificaram que o início do efeito ocorreu após $6 \mathrm{~h}$ da ingestão em 73\% dos casos, com duração de efeito superior a $8 \mathrm{~h}$ em $89 \%$ dos pacientes, o que mantinha os pacientes acordados devido ao efeito laxante do medicamento, quando tomavam o bisacodil às $19 \mathrm{~h}$ da véspera do exame ${ }^{12}$. Em nosso esquema, o laurilsulfato de sódio + sorbitol, por via retal, se mostrou como uma boa alternativa em todas as faixas etárias, sendo de fácil aplicação em $70 \%$ dos casos, com início de efeito em menos de 30 minutos e duração de menos de uma hora, não atrapalhando o sono da criança. O efeito colateral mais comum do Minilaxâ foi dor abdominal, o que também ocorreu com o uso do bisacodil, como relatado nos trabalhos de PINFIELD et al., $1999^{11}$ e TORRES-NETO et al., 20012. Os nossos dados demonstram que se pode substituir o Bisacodil pelo Minilax $₫$ com alguma vantagem.

O fosfato de sódio oral é um agente de limpeza colônica seguro, bem tolerado e efetivo. ${ }^{6}$ Ele pode ser utilizado por via oral ou como enema - Fleet enema®. Vários estudos têm demonstrado a ocorrência de alterações eletrolíticas decorrentes do uso de fosfato de sódio, incluindo aumento dos níveis séricos de fosfato e de sódio, e concomitante diminuição dos níveis séricos de cálcio e potássio, sendo que estas alterações revelaram-se tipicamente reversíveis dentro de aproximadamente 24 horas e não associadas à repercussão clínica. ${ }^{\mathbf{7 8}, 9}$ Pode também provocar dor abdominal, náusea, vômito e vertigem. ${ }^{6}$

Nas crianças com menos de 5 anos, o fosfato de sódio retal se mostrou como uma boa opção, já que, 
além de não depender da vontade da criança, o início do efeito ocorreu em menos de $30 \mathrm{~min}$ em todas elas e obteve-se resultado bom e excelente em $88 \%$ dos casos, semelhante ao observado por ABUBAKAR et al., 1995. ${ }^{3}$ Apesar disso, todas as mães relataram aplicação difícil e a dor abdominal ocorreu em todas as crianças após uso do enema no nosso trabalho. Já PORTORREAL et al., 2000, encontraram dor abdominal em 23,5\% das crianças após o enema fosfatado e concluíram também ser este um método de preparo intestinal eficaz. Além disso, ele deve ser usado com cautela, por poder causar hiperfosfatemia, hipocalcemia e necrose retal depois de repetidas administrações, como relataram ABUBAKAR et. al., 1995, podendo também causar hiperemia leve da mucosa retal, ${ }^{3}$ o que não foi observado em nosso estudo.

O uso de solução oral de manitol em crianças se mostrou eficaz na limpeza colônica da faixa etária preconizada, além de ser de fácil ingestão, apesar de relatos de certa resistência ao final da administração. PORTORREAL et al., 2000, no serviço em que trabalhavam, usavam, de rotina, a solução de manitol, mas, devido à maior morbidade para a criança, eles decidiram testar o preparo com fosfato de sódio retal, que se mostrou, segundo eles, superior ao preparo com manitol, quando avaliados conforto, aceitação da criança e de seus familiares. ${ }^{2}$ Entretanto, acreditamos ser a solução de manitol mais confortável para a criança maior que 5 anos, visto que esta faixa etária já permite uma maior aceitação da solução por via oral, além de ser mais difícil para os pais a administração de enemas nessa idade. Este esquema de preparo intestinal também se mostrou como uma alternativa mais acessível a todas as classes econômicas, pois evita a necessidade de internação hospitalar para que seja administrada a solução por sonda nasogástrica, por exemplo.

O nosso trabalho demonstrou a eficácia de um esquema de preparo intestinal mais individualizado, considerando a ocorrência de resultado bom e excelente em 80,9\% dos exames. Quando o manitol for necessário, pode-se optar pela solução de manitol com sabor artificial (pêssego e uva), obtida em farmácia de manipulação, a fim de se obter uma maior aceitação por parte da criança. Em nosso serviço, já iniciamos a observação também em adultos, com resultados iniciais promissores. Além disso, evidenciou-se que o bisacodil pode ser substituído pelo Minilaxâ, devido ao início e duração de efeitos mais rápidos deste, apesar de eficácia semelhante.

\section{CONCLUSÕES}

Os enteroclismas de fosfato de sódio e Minilaxâ, apesar de mais difícil aplicação, são alternativas eficazes no preparo intestinal, por independerem da colaboração da criança;

Houve baixa morbidade (leves efeitos colaterais como dor abdominal, ardor anal, náuseas e vômitos etc.).

O preparo intestinal individualizado por faixa etária permitiu alto índice de bom e excelente preparo.

\footnotetext{
ABSTRACT: To an accurate colonoscopy procedure it is necessary a satisfactory colonic cleansing. There are many bowel preparation methods for adults, but there is not any ideal method for children. Therefore, this study tried to find a standard method for this age that can associate excellent colonic cleansing, less side effects, higher acceptability and affordability, relatives' support. Forty-six children were evaluated after they had undergone a video colonoscopy, between 2002 and 2006, at the department of video colonoscopy of Hospital Universitário de Sergipe and at UPEP. They were placed in the following groups: children until 1 year old (group A), children from the age of 1 to 5(group B), and children over 5 (group C). In the first and second groups, sodium phosphate was administered via rectum, and in the third group the children received oral manitol solution. From the 25 children that used the rectal sodium phosphate, the preparation was excellent in $22(88 \%)$ and good in $1(4 \%)$, although all the parents emphasized a difficult application. From the other 21 children, that used manitol, $17(80,9 \%)$ had an excellent preparation, $1(4,8 \%)$ had good preparation, $2(9,5 \%)$ had a regular preparation and $1(4,8 \%)$ had a very bad preparation, although all the children had vomited and had felt sick after its ingestion, with low acceptation by the children due to the big volume. The cecum was reached in 41 (89\%) cases, from which $19(41,3 \%)$ had been examined until the terminal ileum. An indivualized prepare allowed great level of good prepare and low morbidity.
}

Key words: Colonoscopy, children, intestinal cleaning, manitol ${ }^{\circledR}$ and sodium phosphate. 


\section{REFERÊNCIAS}

1. Souza, V.C.T. Coloproctologia. $4^{\mathrm{a}}$ edição. Ed. Médica e Científica: Rio de Janeiro, 1999. Cap. 49. pp. 503-511

2. Portorreal, A.; Kawakami, E. Preparo intestinal para colonoscopia com bisacodil oral e solução fosfatada por via retal em crianças e adolescentes. Brazilian Pediatric News, Vol.2, $\mathrm{N}^{\circ}$ 3, Sep 2000.

3. Abubakar, K.; Goggin, N.; Gormally, S.; Durmin, M.; Drumin, B. Preparing the bowel for colonoscopy. Arch Dis Child 73:459-461, 1995.

4. Silva, M.; Briars, G.L.; Patrick, M.K.; Cleghorn, G.J.; Shepherd, R.W. Colonoscopy preparation in children: Safety, efficacy and tolerance of high versus low-volume cleansing methods. J Pediatr Gastroenterol Nutr 24:33-37, 1997.

5. Keeffe, E.B. Colonoscopy preps: What's best? Gastrointestinal Endoscopy 43:5, 524-528, 1996.

6. Unal, S.; Dogan, U.B.; Oztürk, Z.; Cindoruk, M. A randomized prospective trial comparing 45 and $90-\mathrm{ml}$ oral sodium phosphate with X-Prep in the preparation of patients for colonoscopy. Acta Gastroenterol Belg; 61(3):281-4, Belgium, Jun-Sep 1998.

7. Vanner, S.J.; Macdonald, P.H.; Paterson, W.G.; Prentice, R.S.A.; Da Costa, L.R.; Beck, I.T. A randomized prospective trial comparing sodium phosphate with standard polyethylene glycol-based lavage solution (golytely) in the preparation of patients for colonoscopy. Am J Gastroenterology 1990; 85(4):422-27.
8. Ehrenpreis, E.D.; Nogueras, J.J.; Botoman, V.A.; Bonner, G.F.; Zaitman, D.; Secrest, K.M. Serum electrolyte abnormalities secondary to Fleets Phospho-Soda colonoscopy prep. Surg Endosc 1996; 1022-1024.

9. Lieberman, D.A.; Ghormley, J.; Flora, K. Effect of oral sodium phosphate colon preparation on serum electrolytes in patients with normal serum creatinine. Gastrointestinal Endoscopy 1996; 43(5):467-69.

10. Dipalma, J.; Brandy, C.; Steward, D.; Karlin, D.; Mckinney, K.; Clement, D. et al. Comparison of colon cleansing methods in preparation for colonoscopy. Gastroenterology 86:856-60, 1984.

11. Pinfield, A.; Stringer, M.D. Randomized trial of two pharmacological methods of bowel preparation for day case colonoscopy. Arch Dis Child; 80(2):181-3, England, Fev. 1999.

12. Torres-Neto, J.R.; Vidal, M.A.N.; Santana, N.M.B.; Alves, M.C.; Hora, I.C.M. Avaliação do início e da duração do efeito do Bisacodil. Tema livre do XIX Cong Reg N/NE de Coloproctologia. Brasil, Abril 2001.

\section{Endereço para correspondência:}

JUVENAL DA ROCHA TORRES NETO

Rua Ananias Azevedo No 100, apto. 902. Bairro Praia 13 de Julho Aracaju - SE

E-mail: jtorres@infonet.com.br Tel.(fax).: (79) 32144830 